\title{
High Sensitivity CRP Predicts Long-Term Mortality in Patients with Atrial Fibrillation and Evident Acute Coronary Syndrome
}

\author{
Christoph Liebetrau ${ }^{1,2^{*}}$, Luise Gaede ${ }^{1 \#}$, Sebastian Szardien ${ }^{1}$, Johannes Rixe ${ }^{2}$, Oliver Doerr ${ }^{2}$, \\ Matthias Willmer ${ }^{1}$, Michael Weber ${ }^{1}$, Andreas Rolf ${ }^{1,2}$, Helge Möllmannn ${ }^{1,2}$, Albrecht Elsässer ${ }^{1}$, \\ Christian Hamm ${ }^{1,2}$, Holger Nef ${ }^{1,2}$
}

${ }^{1}$ Department of Cardiology, Kerckhoff Heart and Thorax Center, Bad Nauheim, Germany; ${ }^{2}$ Department of Cardiology and Angiology, Faculty of Medicine, Justus-Liebig University of Giessen, Giessen, Germany.

Email: ${ }^{*}$ c.liebetrau@kerckhoff-klinik.de

Received December $7^{\text {th }}, 2012$; revised March $3^{\text {rd }}, 2013$; accepted March $14^{\text {th }}, 2013$

\begin{abstract}
Background: Atrial fibrillation (AF) is a frequent arrhythmia associated with an adverse prognostic value in patients with ACS. Risk stratification as well as diagnosis of ACS is strongly supported by biomarkers. High sensitivity CRP (hs-CRP) is known to be elevated in patients presenting with ACS as well as with AF. Methods: In total, 2034 consecutive patients with an ACS were analysed. The incidence of AF in the setting of ACS, the prognostic value of hs-CRP and the clinical outcome within 6 months were subject of the study. Death after 6 months was considered as primary endpoint. Results: The frequency of AF among patients admitted with suspected ACS was 124 (6.1\%). During 6-month follow-up the mortality rate among patients with AF was significantly higher (20 [16.1\%] vs 133 [6.9\%]; logrank 13.72; $p<0.001)$ compared to patients without AF. Cox regression analysis revealed an increased risk for ACS patients with AF with an adjusted HR of $2.63(95 \%$ CI $1.48-3.78 ; p<0.001)$. Patients with AF showed significant higher levels of hs-CRP than patients without AF $(6.01 \mathrm{mg} / \mathrm{dl}$ IQR [1.7 - 17.8] vs 3.3mg/dl IQR [1.37 - 9.83]; $p=0.003)$. By the use of multivariate Cox regression analysis, risk of mortality was higher when AF patients had higher concentrations of hs-CRP (HR 1.076; 95\% CI $1.02-1.13 ; p=0.002)$. Conclusions: AF is a strong and independent indicator for increased mortality in patients presenting with ACS. hs-CRP predicts mortality in AF patients and should be considered for risk stratification in clinical routine.
\end{abstract}

Keywords: Acute Coronary Syndrome; Atrial Fibrillation; Risk Stratification; High-Sensitivity CRP

\section{Introduction}

Atrial fibrillation (AF) is the most common arrhythmia in the general population and is linked with relevant morbidity and mortality $[1,2]$. The prevalence of $\mathrm{AF}$ in patients with stable coronary artery disease is described with less frequency compared to patients without cardiovascular disease [3]. But due to growing life expectancy the number of patients with AF and cardiovascular disease will increase [4]. At the moment the prevalence of pre-existing and/or new-onset AF in acute coronary syndromes (ACS) ranges from 5\% to $21 \%$ [5-8]. Data from several studies showed that new-onset $\mathrm{AF}$ in the setting of acute myocardial infarction has been associated as an independent risk factor for in-hospital and longterm mortality [5-10]. Nevertheless, at the moment AF is

\footnotetext{
"Corresponding author.

"These authors contributed equally.
}

not part of the common risk scores such as the GRACEscore.

Risk stratification in patients with ACS is still a daily clinical challenge [11]. Therefore, biomarkers play a central role providing both diagnostic and prognostic information. Studies have shown that various biomarkers can predict a poor prognosis in patients with ACS [12, 13]. Besides the well established markers cardiac troponin and NT-pro Brain Natriuretic Peptide [14,15], also inflammatory markers are known to be of prognostic value [16-19].

Especially high sensitivity CRP is associated with cardiovascular risk and coronary events [20-23]. It is associated with culprit lesion plaque rupture in ACS as well as with adverse outcome after myocardial infarction [16, $17,24,25]$. On the other hand there is emerging data which support an association between inflammation and AF. In this context hs-CRP is described to predict mor- 
tality in patients with AF [26-28]. Therefore, CRP seems to be an interesting prognostic marker in patients with ACS as well as in patients with AF.

The aim of the present study was to evaluate the prognostic value of hs-CRP in patients with ACS complicated by coexistent AF. Furthermore we wanted to show the impact of AF and hs-CRP on the clinical outcome at 6 months follow-up.

\section{Methods}

\subsection{Patients and Treatment}

2034 consecutive patients submitted with an episode of chest pain within the last $48 \mathrm{~h}$ and suspected ACS were included into the registry. For the present analysis all patients were included. Patients were considered to be at high risk if they were in cardiogenic shock, under mandatory ventilation or admitted after successful CPR. Cardiogenic shock was defined as reduced blood pressure (systolic $\mathrm{BP}<90 \mathrm{mmHg}$ or a drop of mean arterial pressure $>30 \mathrm{mmHg})$ and $/$ or low urine output $(<0.5 \mathrm{ml} / \mathrm{kg} / \mathrm{h})$, with a pulse rate $>60$ b.p.m. [29]. PCI was performed according to standard clinical practice. Left ventricular ejection fraction was routinely measured within the first day after admission for the index event during hospitalization.

Diabetes mellitus was defined by the presence in medication with oral antidiabetics or insulin. Hyperlipoproteinaemia was defined by chronic use of statins or by LDL-cholesterol levels $\geq 160 \mathrm{mg} / \mathrm{dl}$. The definition of hypertension was made by the chronic use of antihypertensive drugs.

The patients were enrolled in the AF group based on the ECG on admission. Pre-history of AF was not evaluated given the fact that $\mathrm{AF}$ was shown as a risk factor irrespective of new-onset or preexisting AF $[9,30]$. AF was defined and categorised using an adaption of the 2006 Guidelines from the American College of Cardiology, American Heart Association and European Heart Associaton [31]. Atrial fibrillation was defined as the absence of $P$ waves, and atrial activity was represented by fibrillatory waves and/or irregular time elapsing between 2 consecutive $R$ wave (RR) intervals.

Patients were followed over 6 months. With regard to ACS and AF patients medication was recommended towards rate control and anticoagulation following the guidelines [31]. Risk stratification for thromboembolism and need for anticoagulation was evaluated and recommended by the use of CHADS2-Score. Death after 6 months was the primary endpoint. Follow up data was achieved during a personal visit, which has been afforded by $84 \%$ of patients. The remaining patients, their relatives or general physicians were contacted by telephone to get the absent information.

\subsection{Laboratory Assessment}

Venous blood samples were collected on admission and the day after in plain and EDTA-containing tubes for determination of the various biomarkers. The serum and EDTA-plasma were processed immediately and frozen at $-80^{\circ} \mathrm{C}$ until assayed.

\subsection{Statistical Analysis}

Data for categorical variables are expressed as number and percentage of patients. For continuous variables, data are reported as means \pm SD or median and interquartile range when appropriate. Values were compared by unpaired Student's t-tests after testing for normal distribution. Fisher's exact test or chi-square test was used for categorical variables with nominal scales, and the MannWhitney-U rank-sum test was used for those with ordinal scales. Multivariate Cox regression analysis was used to calculate Hazard ratios. Univariate Cox regression analyses were performed with mortality as the outcome variable. The following univariate predictors were tested: age, gender, BMI, hypertension, hyperlipoproteinaemia, diabetes mellitus, current smoking, family history of CAD, prior CAD (prior AMI, prior PCI, prior CABG), time limits (onset of symptoms until 1st medical contact, 1 st medical contact until admission PCI center), left ventricular ejection fraction, high risk patients, $\mathrm{CAD}$ severity (1-, 2-, 3-vessel CAD), treatment (PCI, CABG, conservative), $\mathrm{CK}-, \mathrm{CK}-\mathrm{MB}$, cardiac troponin $\mathrm{T}$ on admission and the day after, serum creatinine, high sensitivity (hs-) CRP and NT-proBNP on admission. Univariate predictors with $p \leq 0.10$ were entered into multivariate Cox regression analysis. For the clinical endpoints the Kaplan-Meier method was applied and differences assessed by the log-rank test. All statistical tests were performed with SPSS software, version 15.0. A 2-tailed $p$-value < 0.05 was considered statistically significant.

\section{Results}

A total of 2034 consecutive patients with suspected ACS were included in the registry. In 124 (6.1\%) patients the diagnosis of AF was additionally made. Patients with $\mathrm{AF}$ and those without $\mathrm{AF}$ were assigned to $\mathrm{AF}$ group $(\mathrm{n}=$ $124)$ and Non-AF group $(n=1910)$.

Patients with AF were significantly older and had significantly more hypertension, higher heart rate, lower systolic blood pressure on admission and lower ejection fraction at baseline. More current smokers and patients with family history for CAD were seen in the Non-AF group. Looking for high-risk patients revealed that sig- 
nificantly more patients were found in the AF group (32 [25.8\%] vs 281 [14.8\%]; $p<0.01)$. For all other clinical parameters no significant differences have been observed (Table 1).

There was no difference in the median time delay from onset of symptoms until first medical contact (AF group $1.5 \mathrm{~h}$ IQR [0.5 - 4.0] vs Non-AF group 1.4 h IQR [0.5 $4.5] ; p=0.82$ ). However, a trend in time delay from first medial contact until admission in the PCI center could be observed in the AF group (AF group 2.0 h IQR [1.2 - 7.7] vs Non-AF group 1.5 h IQR [1.0 - 4.5]; $p=0.06$ ).

Patients with AF had higher levels of serum creatinine $(1.0 \mathrm{mg} / \mathrm{dL}$ IQR $[0.83-1.24]$ vs $0.89 \mathrm{mg} / \mathrm{dL}$ IQR [0.76 $1.14] ; p<0.001)$ and hs-CRP $(6.01 \mathrm{mg} / \mathrm{dL}$ IQR $[1.7-$ $17.8]$ vs $3.3 \mathrm{mg} / \mathrm{dl}$ IQR [1.37 - 9.83]; $p=0.003)$. A trend to higher cardiac troponin $\mathrm{T}$ concentrations on admission could be observed in the AF group (25.0 ng/L IQR [10.0 69.0] vs $11.0 \mathrm{ng} / \mathrm{L}$ IQR $[<10.0-68.0] ; p=0.08)$ (Ta- ble 2). There was no difference in CK- or CK-MB levels between the groups on admission as well as on day 1 after admission (Table 2).

There were significantly more patients with multi vessel disease (34 [27.4\%] vs 368 [19.3\%]; $p=0.03$ ) in the AF group. Patients with AF underwent PCI to a significant lesser extent (82 [66.1\%] vs 1423 [74.5\%]; $p=0.03$ ) Contrarily, more patients had undergo emergency CABG $(16[12.9 \%]$ vs $85[4.5 \%] ; p<0.001)$. In total, 428 patients were treated conservatively (Table 2).

\section{Follow-Up}

During 6-month follow-up the mortality rate among the patients with AF was significantly higher $(20$ [16.1\%] vs 133 [6.9\%]; Log Rank 13.72; $p<0.001$ ) compared to patients without AF (Table 3, Figure 1). The mortality rate still differed by excluding high-risk patients from the

Table 1. Baseline characteristics of patients.

\begin{tabular}{|c|c|c|c|}
\hline Variable & AF group $(n=124)$ & Non-AF group $n=(1910)$ & $p$ value \\
\hline Age (years), mean \pm SD & $71.9 \pm 13.4$ & $63.1 \pm 13.3$ & $<0.001$ \\
\hline Male sex, n (\%) & $80(64.5)$ & $1335(70.2)$ & 0.36 \\
\hline Body-mass-index $\left(\mathrm{kg} / \mathrm{m}^{2}\right)$, mean $\pm \mathrm{SD}$ & $28.4 \pm 4.5$ & $27.8 \pm 4.5$ & 0.53 \\
\hline \multicolumn{4}{|l|}{ Cardiovascular risk factors, $\mathrm{n}(\%)$} \\
\hline Current Smoking & $21(16.9)$ & $608(31.9)$ & $<0.001$ \\
\hline Hypertension & $95(76.6)$ & $1264(66.4)$ & 0.02 \\
\hline Hyperlipoproteinaemia & $43(34.7)$ & 799 (41.9) & 0.13 \\
\hline Diabetes mellitus & $34(27.4)$ & $401(21.1)$ & 0.09 \\
\hline Family history of CAD & $7(5.6)$ & $320(16.8)$ & $<0.01$ \\
\hline \multicolumn{4}{|l|}{ History of CAD, n (\%) } \\
\hline Previous myocardial infarction & $15(12.1)$ & $255(13.4)$ & 0.79 \\
\hline Previous CABG & $11(8.9)$ & $143(7.5)$ & 0.59 \\
\hline Previous PCI & $11(8.9)$ & $236(12.4)$ & 0.26 \\
\hline \multicolumn{4}{|l|}{ ACS-Event, n (\%) } \\
\hline ST-Elevation Myocardial Infarction & $50(40.3)$ & $900(47.1)$ & 0.07 \\
\hline Non-ST-Elevation Myocardial Infarction & $39(31.5)$ & $449(23.5)$ & 0.08 \\
\hline Unstable Angina & $19(15.3)$ & $257(13.5)$ & 0.89 \\
\hline Patients without ACS, n (\%) & $14(11.3)$ & $304(15.9)$ & 0.36 \\
\hline Systolic BP (mmHg), mean \pm SD & $128.6 \pm 37.9$ & $135.5 \pm 33.2$ & 0.04 \\
\hline Heart rate $(\mathrm{bpm})$, mean $\pm \mathrm{SD}$ & $83.3 \pm 31.0$ & $75.2 \pm 19.4$ & $<0.001$ \\
\hline $\mathrm{LV}$ ejection fraction $(\%)$, mean $\pm \mathrm{SD}$ & $42.2 \pm 11.4$ & $47.9 \pm 10.9$ & $<0.01$ \\
\hline High risk patients, n (\%) & $32(25.8)$ & $281(14.8)$ & $<0.01$ \\
\hline
\end{tabular}


Table 2. Laboratory measurements and angiographic characteristics.

\begin{tabular}{|c|c|c|c|}
\hline Variable & AF group $(n=124)$ & Non-AF group $n=(1910)$ & $p$ value \\
\hline \multicolumn{4}{|l|}{ Laboratory measurements, median (IQR) } \\
\hline Serum creatinine $(\mathrm{mg} / \mathrm{dL})$ on admission & $1.0(0.8-1.2)$ & $0.89(0.8-1.1)$ & $<0.001$ \\
\hline High sensitive CRP $(\mathrm{mg} / \mathrm{dL})$ on admission & $6.01(1.7-17.8)$ & $3.30(1.37-9.83)$ & 0.003 \\
\hline Cardiac troponin $\mathrm{T}(\mathrm{ng} / \mathrm{L})$ on admission & $25.0(10.0-69.0)$ & $11.4(<10.0-68.2)$ & 0.08 \\
\hline Cardiac troponin $\mathrm{T}(\mathrm{ng} / \mathrm{L})$ 1st day & $491.0(62.0-1880.0)$ & $383.0(10.0-1820.0)$ & 0.13 \\
\hline CK (U/l) on admission & $153.0(92.0-309.5)$ & $157.0(71.0-420.0)$ & 0.96 \\
\hline CK (U/l) 1st day & $394.0(130.0-1161.0)$ & $350.0(103.3-1123.8)$ & 0.31 \\
\hline CK-MB (U/l) on admission & $7.6(3.3-24.0)$ & $8.6(3.4-34.4)$ & 0.66 \\
\hline CK-MB (U/l) 1st day & $13.0(5.5-44.7)$ & $18.8(5.0-65.5)$ & 0.31 \\
\hline NT-proBNP (ng/L) on admission & $257.0(74.8-758.8)$ & $228.0(78.0-698.0)$ & 0.90 \\
\hline \multicolumn{4}{|l|}{ CAD severity, n (\%) } \\
\hline No CAD & $14(11.3)$ & $272(14.2)$ & 0.35 \\
\hline Coronary sclerosis & $3(2.4)$ & $37(1.9)$ & 0.27 \\
\hline 1-vessel disease & $40(32.3)$ & $750(39.3)$ & 0.12 \\
\hline 2-vessel disease & $33(26.6)$ & $483(25.3)$ & 0.84 \\
\hline 3-vessel disease & $34(27.4)$ & $368(19.3)$ & 0.03 \\
\hline \multicolumn{4}{|l|}{ Treatment, n (\%) } \\
\hline PCI & $82(66.1)$ & $1423(74.5)$ & 0.03 \\
\hline CABG & $16(12.9)$ & $85(4.5)$ & $<0.001$ \\
\hline Conservative & $26(21.0)$ & $402(21.0)$ & 0.73 \\
\hline
\end{tabular}

Table 3. Major adverse cardic events at 6 months follow-up.

\begin{tabular}{cccc}
\hline Variable & AF group $(\mathrm{n}=124)$ & Non-AF group $(\mathrm{n}=1910)$ & $p$ value \\
\hline Death, $\mathrm{n}(\%)$ & $20(16.1)$ & $133(7.0)$ & $<0.01$ \\
Myocardial infarction, $\mathrm{n}(\%)$ & $0(0)$ & $24(1.3)$ & 0.17 \\
Repeat revascularization, $\mathrm{n}(\%)$ & $9(7.2)$ & $90(4.7)$ & \\
PCI, $\mathrm{n}(\%)$ & $6(4.8)$ & $74(3.9)$ & $>0.99$ \\
CABG, $\mathrm{n}(\%)$ & $3(2.4)$ & $16(0.8)$ & 0.43 \\
Any major adverse cardiac event, $\mathrm{n}(\%)$ & $29(23.4)$ & $247(12.9)$ & $<0.001$ \\
\hline
\end{tabular}

analysis (Figure 2). Furthermore, significant differences were also found for major adverse cardiac events (death, PCI, CABG, acute myocardial infarction) within 6 months (Table 3).

Kaplan-Meier survival analysis and Cox regression analysis revealed an increased risk for AF patients with an adjusted HR of 2.63 (95\% CI $1.48-3.78 ; p<0.001$ ). After exclusion of patients with documented malignant and infectious disease the multivariate Cox regression analysis showed that risk of mortality was higher when patients with AF had higher concentrations of hs-CRP (HR 1.076; 95\% CI $1.02-1.13 ; p=0.002$ ) and higher CK concentrations (HR 1.001; 95\% CI $1.0-1.002 ; p=$ $0.044)$ as well as higher CK-MB concentrations the day after admission (HR 1.017; 95\% CI 1.002 - 1.031; $p=$ 0.025) (Table 4). 
High Sensitivity CRP Predicts Long-Term Mortality in Patients with

Table 4. Patients with AF: hazard ratios and 95\% CIs on logarithmic scale.

\begin{tabular}{|c|c|c|c|c|}
\hline \multirow{2}{*}{ Variable } & \multirow{2}{*}{ HR } & \multicolumn{2}{|c|}{ CI $95 \%$} & \multirow{2}{*}{$p$ value } \\
\hline & & Lower & Upper & \\
\hline Multi vessel CAD & 0.22 & 0.02 & 2.25 & 0.20 \\
\hline High-risk patients & 7.53 & 0.08 & 731.94 & 0.39 \\
\hline High sensitive CRP (mg/dL) & 1.08 & 1.02 & 1.11 & $<0.01$ \\
\hline Serum creatinine $(\mathrm{mg} / \mathrm{dL})$ & 1.47 & 0.13 & 16.69 & 0.76 \\
\hline $\mathrm{CK}(\mathrm{U} / \mathrm{l}) 1$ st day & 1.00 & 1.00 & 1.00 & 0.04 \\
\hline CK-MB (U/l) 1st day & 1.02 & 1.00 & 1.03 & 0.03 \\
\hline Cardiac Troponin T (ng/L) & 0.75 & 0.33 & 1.73 & 0.50 \\
\hline Cardiac Troponin T (ng/L) 1st day & 0.94 & 0.78 & 1.12 & 0.49 \\
\hline
\end{tabular}

Kaplan-Meier survival curve without high risk patients



Figure 1. Kaplan-meier survival curve for the entire cohort.

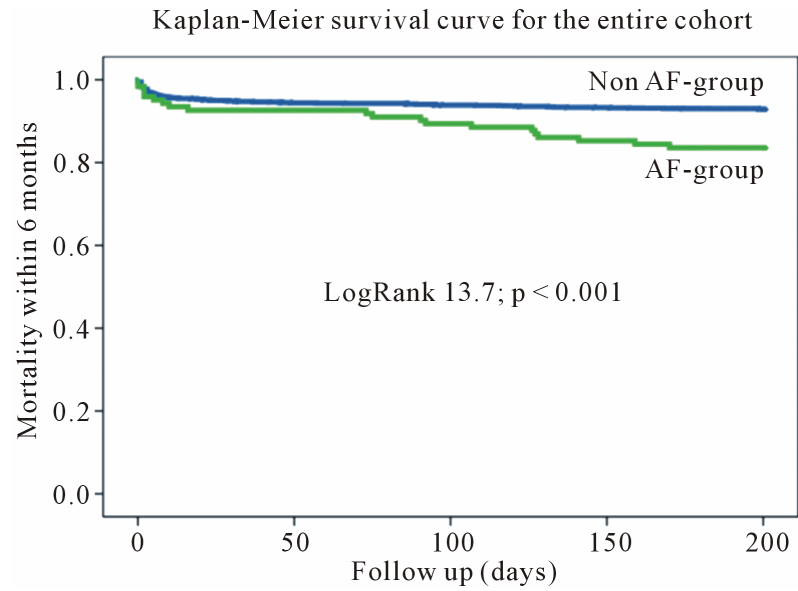

Figure 2. Kaplan-meier survival curve without high-risk patients.

\section{Discussion}

Recently published data have illustrated AF in patients with ACS as an important risk factor irrespective of new- onset or preexisting AF [9,30]. Early invasive strategies in patients with ACS decreased the rate of death and/or recurrence of myocardial infarction [32]. Despite this early revascularization, the morbidity and mortality rate of patients with ACS remains high, particularly when complicated with AF.

The aim of the study was to evaluate the prognostic value of hs-CRP in patients with ACS complicated by AF. Furthermore we wanted to show the impact of AF and hs-CRP on the clinical outcome at 6 months followup.

The main findings are: First, AF is common in patients hospitalized with ACS. The number of affected patients in this study is comparable to other registries [5,7-9]. Second, patients presenting with ACS complicated by AF showed a higher morbidity and mortality rate compared to patients without AF. This difference in clinical outcome persists even after exclusion of high-risk patients from the analyses. Third, patients with ACS and AF had significant higher concentrations of high-sensitive CRP compared to patients without AF. Furthermore, hs-CRP predicted long-term mortality in patients with ACS and coexisting AF.

In the coming decades the number of patients with ACS and coexisting AF will increase due to the demographic change. The independent effect of AF as well as ACS complicated by AF causing higher short- and longterm morbidity and mortality rates is well known [4,5,7-9, 33]. The identification of patients being at high-risk will be a challenge in daily clinical routine.

Our data confirms the increase of long-term mortality in ACS patients due to AF as a comorbidity. Interestingly, the adverse outcome of AF patients was not restricted to high-risk patients which were defined by the presence of cardiogenic shock. However, patients with AF were more often unstable. AF causing higher ventricular rates and consecutively less ventricular filling ensuing cardiac de- 
compensation could explain this higher percentage of hemodynamic unstable patients. Our results showed no significant difference in levels of troponin $\mathrm{T}$ or $\mathrm{CK}$ between the two groups. That confirms that AF is an important risk factor for mortality in patients with ACS independent of the size of myocardial necrosis. These findings are congruent with the results of GRACE [7]. Furthermore, hs-CRP seems to be the only marker allowing additional risk prediction on top of traditional markers mirroring myocardial necrosis.

The AF group showed higher hs-CRP levels than the non-AF group. That supports previous findings, which showed an association between inflammation and AF. A longer duration of $\mathrm{AF}$ is also associated with higher hs-CRP concentrations [26-28]. Furthermore, recent studies could demonstrate that CRP predicts left ventricular ejection fraction and infarct sized measured by magnet resonance imaging 3 months after AMI [34].

The most important finding of our study was that inside the AF group hs-CRP could be of prognostic value for mortality within 6 months after ACS. That confirms the influence of high levels of CRP on culprit lesion plaque rupture in ACS. In this context higher CRP levels were associated with adverse outcome after ACS $[16,17$, $24,25]$. ACS are triggered by inflammatory response and plaque degradation [35]. These previous findings as well as our results support a link between increased risk of more plaque ruptures, followed by a worse clinical outcome, in patients with AF and higher hs-CRP levels compared to those with normal CRP levels $[24,25,28,36]$. Our study confirms the elevation of hs-CRP and the role of inflammation in both morbidities ACS and AF regarding the clinical outcome. The important role of inflammatory processes determining plaque stability supports the possible benefits of lifestyle modification and drug therapy with statins and/or antioxidants [37].

In future studies a focus should be the possibilities to influence the inflammation in patients with AF controlled by hs-CRP levels with either lifestyle modification or drug therapy, e.g. with statin or antioxidants [38-40]. On this way both $\mathrm{AF}$ and vulnerable plaque rupture might be prevented.

At the moment common risk scores for ACS still neglect $\mathrm{AF}$ as an independent implicator for higher mortality rates. Thus, risk stratification and pharmacotherapeutic treatment in these special patients collective should be reconsidered in order to improve prognosis [41]. The risk stratification according to AF could be supported by determination of hs-CRP.

\section{Conclusion}

Atrial fibrillation is a strong and independent indicator for increased mortality in patients presenting with ACS.
Hs-CRP levels in patients with ACS are higher when AF is coexistent. It predicts mortality in patients with ACS complicated by AF and should be considered for risk stratification and pharmacotherapeutic interventions in clinical routine.

\section{REFERENCES}

[1] T. S. Tsang, Y. Miyasaka, M. E. Barnes, et al., "Epidemiological Profile of Atrial Fibrillation: A Contemporary Perspective," Progress in Cardiovascular Diseases, Vol. 48, No. 1, 2005, pp. 1-8. doi:10.1016/j.pcad.2005.06.001

[2] E. J. Benjamin, P. A. Wolf, R. B. D'Agostino, et al., "Impact of Atrial Fibrillation on the Risk of Death: The Framingham Heart Study," Circulation, Vol. 98, 1998, pp. 946-952. doi:10.1161/01.CIR.98.10.946

[3] A. Cameron, M. J. Schwartz, R. A. Kronmal, et al., "Prevalence and Significance of Atrial Fibrillation in Coronary Artery Disease (CASS Registry)," American Journal of Cardiology, Vol. 61, No. 10, 1988, pp. 714-717. doi:10.1016/0002-9149(88)91053-3

[4] N. R. Desai and R. P. Giugliano, "Can We Predict Outcomes in Atrial Fibrillation?" Clinical Cardiology, Vol. 35, Suppl. 1, 2012, pp. 10-14. doi:10.1002/clc.20989

[5] R. D. Lopes, K. S. Pieper, J. R. Horton, et al., "Short- and Long-Term Outcomes Following Atrial Fibrillation in $\mathrm{Pa}$ tients with Acute Coronary Syndromes with or without ST-Segment Elevation," Heart, Vol. 94, No. 7, 2008, pp. 867-873. doi:10.1136/hrt.2007.134486

[6] J. Schmitt, G. Duray, B. J. Gersh, et al., "Atrial Fibrillation in Acute Myocardial Infarction: A Systematic Review of the Incidence. Clinical Features and Prognostic Implications," European Heart Journal, Vol. 30, No. 9, 2009, pp. 1038-1045. doi:10.1093/eurheartj/ehn579

[7] R. H. Mehta, O. H. Dabbous, C. B. Granger, et al. (For the GRACE Investigators), "Comparison of Outcomes of Patients with Acute Coronary Syndromes with and without Atrial Fibrillation," American Journal of Cardiology, Vol. 92, No. 9, 2003, pp. 1031-1036. doi:10.1016/j.amjcard.2003.06.001

[8] S. S. Rathore, A. K. Berger, K. P. Weinfurt, et al., "Acute Myocardial Infarction Complicated by Atrial Fibrillation in the Elderly: Prevalence and Outcomes," Circulation, Vol. 101, 2000, pp. 969-974. doi:10.1161/01.CIR.101.9.969

[9] D. Poci, M. Hartford, T. Karlsson, et al., "Effect of New Versus Known versus No Atrial Fibrillation on 30-Day and 10-Year Mortality in Patients with Acute Coronary Syndrome," American Journal of Cardiology, Vol. 110, No. 2, 2012, pp. 217-221.

[10] P. Jabre, X. Jouven, F. Adnet, G. Thabut, S. J. Bielinski, S. A. Weston and V. L. Roger, "Atrial Fibrillation and Death after Myocardial Infarction: A Community Study," Circulation, Vol. 123, No. 19, 2011, pp. 2094-2100. doi:10.1161/CIRCULATIONAHA.110.990192

[11] R. F. Alcock, A. S. Yong, A. C. Ng, et al., "Acute Coronary Syndrome and Stable Coronary Artery Disease: Are 
They So Different? Long-Term Outcomes in a Contemporary PCI Cohort," International Journal of Cardiology, 2012. doi:10.1016/j.ijcard.2012.04.011

[12] C. Heeschen, S. Dimmeler, C. W. Hamm, et al., "CAPTURE Study Investigators. Pregnancy-Associated Plasma Protein-A Levels in Patients with Acute Coronary Syndromes: Comparison with Markers of Systemic Inflammation, Platelet Activation, and Myocardial Necrosis," Journal of the American College of Cardiology, Vol. 45, No. 2, 2005, pp. 229-237. doi:10.1016/j.jacc.2004.09.060

[13] S. Q. Khan, O. S. Dhillon, R. J. O’Brien, et al., "C-Terminal Provasopressin (Copeptin) as a Novel and Prognostic Marker in Acute Myocardial Infarction: Leicester Acute Myocardial Infarction Peptide (LAMP) Study," Circulation, Vol. 115, 2007, pp. 2103-2110. doi:10.1161/CIRCULATIONAHA.106.685503

[14] M. Weber, O. Bazzino, J. L. Navarro Estrada, et al., "Improved Diagnostic and Prognostic Performance of a New High-Sensitive Troponin T Assay in Patients with Acute Coronary Syndrome," American Heart Journal, Vol. 162, No. 1, 2011, pp. 81-88. doi:10.1016/j.ahj.2011.04.007

[15] S. A. Kim, S. J. Rhee, C. Y. Shim, et al., "Prognostic Value of N-Terminal Probrain Natriuretic Peptide Level on Admission in Patients with Acute Myocardial Infarction and Preserved Left Ventricular Ejection Fraction," Coronary Artery Disease, Vol. 22, No. 3, 2011, pp. 153157. doi:10.1097/MCA.0b013e3283423622

[16] M. Hartford, O. Wiklund, L. Mattsson-Hulten, et al., "CReactive Protein, Interleukin-6, Secretory Phospholipase A2 Group IIA and Intercellular Adhesion Molecule-1 in the Prediction of Late Outcome Events after Acute Coronary Syndromes," Journal of Internal Medicine, Vol. 262, No. 5, 2007, pp. 526-536.

[17] M. N. Zairis, E. N. Adamopoulou, S. J. Manousakis, et al. (Biomarkers of Inflammation and Outcome in Acute Coronary Syndromes (BIAS) Investigators), "The Impact of hs C-Reactive Protein and Other Inflammatory Biomarkers on Long-Term Cardiovascular Mortality in Patients with Acute Coronary Syndromes," Atherosclerosis, Vol. 194, No. 2, 2007, pp. 397-402. doi:10.1016/j.atherosclerosis.2006.08.008

[18] B. Lindahl, H. Toss, A. Siegbahn, P. Venge and L. Wallentin, "Markers of Myocardial Damage and Inflammation in Relation to Long-Term Mortality in Unstable Coronary Artery Disease. FRISC Study Group. Fragmin during Instability in Coronary Artery Disease," New England Journal of Medicine, Vol. 343, 2000, pp. 1139-1147. doi:10.1056/NEJM200010193431602

[19] C. Mueller, H. J. Buettner, J. M. Hodgson, et al., "Inflammationandlong-Term Mortality after Non-ST-Elevation Acute Coronary Syndrome Treated with a Very Early Invasive Strategy in 1042 Consecutive Patients," Circulation, Vol. 105, 2002, pp. 1412-1415. doi:10.1161/01.CIR.0000012625.02748.62

[20] F. Haverkate, S. G. Thompson, S. D. M. Pyke, J. R. Gallimore and M. B. Pepys, "Production of C-Reactive Protein and Risk of Coronary Events in Stable and Unstable Angina," Lancet, Vol. 349, No. 9050, 1997, pp. 462-466. doi:10.1016/S0140-6736(96)07591-5
[21] P. M. Ridker, M. Cushman, M. J. Stampfer, R. P. Tracy and C. H. Hennekens, "Inflammation, Aspirin, and the Risk of Cardiovascular Disease in Apparently Healthy Men," New England Journal of Medicine, Vol. 336, 1997, pp. 973-979. doi:10.1056/NEJM199704033361401

[22] W. Koenig, M. Sund, M. Frohlich, H. G. Fischer, H. Lowel, A. Doring, et al., "C-Reactive Protein, a Sensitive Marker of Inflammation, Predicts Future Risk of Coronary Heart Disease in Initially Healthy Middleaged Men: Results from the MONICA (Monitoring Trends and Determinants in Cardiovascular Disease) Augsburg Cohort Study, 1984 to 1992," Circulation, Vol. 99, 1999, pp. 237-242. doi:10.1161/01.CIR.99.2.237

[23] R. Rückerl, A. Peters, N. Khuseyinova, et al., "Determinants of the Acute-Phase Protein C-Reactive Protein in Myocardial Infarction Survivors: The Role of Comorbidities and Environmental Factors," Clinical Chemistry, Vol. 55, No. 2, 2009, pp. 322-335.

[24] T. Sano, A. Tanaka, M. Namba, et al., "C-Reactive Protein and Lesion Morphology in Patients with Acute Myocardial Infarction," Circulation, Vol. 108, 2003, pp. 282285. doi:10.1161/01.CIR.0000079173.84669.4F

[25] H. Otake, J. Shite, T. Shinke, et al., "Relation between Plasma Adiponectin, High-Sensitivity C-Reactive Protein, and Coronary Plaque Components in Patients with Acute Coronary Syndrome," American Journal of Cardiology, Vol. 101, No. 1, 2008, pp. 1-7. doi:10.1016/j.amjcard.2007.07.041

[26] M. K. Chung, D. O. Martin, D. Sprecher, et al., "CReactive Protein Elevation in Patients with Atrial Arrhythmias: Inflammatory Mechanisms and Persistence of Atrial Fibrillation," Circulation, Vol. 104, 2001, pp. 28862891. doi: $10.1161 /$ hc4901.101760

[27] E. Hatzinikolaou-Kotsakou, D. Tziakas, A. Hotidis, et al., "Relation of C-Reactive Protein to the First Onset and the Recurrence Rate in Lone Atrial Fibrillation," American Journal of Cardiology, Vol. 97, No. 5, 2006, pp. 659-661. doi:10.1016/j.amjcard.2005.09.104

[28] J. Hermida, F. L. Lopez, R. Montes, et al., "Usefulness of High-Sensitivity C-Reactive Protein to Predict Mortality in Patients with Atrial Fibrillation (from the Atherosclerosis Risk In Communities [ARIC] Study)," American Journal of Cardiology, Vol. 109, No. 1, 2012, pp. 95-99. doi:10.1016/j.amjcard.2011.08.010

[29] J. J. McMurray, S. Adamopoulos, S. D. Anker, et al., "ESC Guidelines for the Diagnosis and Treatment of Acute and Chronic Heart Failure 2012: The Task Force for the Diagnosis and Treatment of Acute and Chronic Heart Failure 2012 of the European Society of Cardiology. Developed in collaboration with the Heart Failure Association (HFA) of the ESC," European Heart Journal, Vol. 33, No. 14, 2012, pp. 1787-1874.

[30] D. H. Lau, L. T. Huynh, D. P. Chew, et al., "Prognostic Impact of Types of Atrial Fibrillation in Acute Coronary Syndromes," American Journal of Cardiology, Vol. 104, No. 10, 2009, pp. 1317-1323. doi:10.1016/j.amjcard.2009.06.055

[31] V. Fuster, L. E. Ryden, D. S. Cannom, H. J. Crijns, et al., "ACC/AHA/ESC 2006 Guidelines for the Management 
of Patients with Atrial Fibrillation: A Report of the American College of Cardiology/American Heart Association Task Force on Practice Guidelines and the European Society of Cardiology Committee for Practice Guidelines (Writing Committee to Revise the 2001 Guidelines for the Management of Patients with Atrial Fibrillation): Developed in Collaboration with the European Heart Rhythm Association and the Heart Rhythm Society," Circulation, Vol. 114, 2006, pp. e257-e354. doi:10.1161/CIRCULATIONAHA.106.177292

[32] K. A. Fox, T. C. Clayton, P. Damman, et al., "Long-Term Outcome of a Routine versus Selective Invasive Strategy in Patients with Non-ST-Segment Elevation Acute Coronary Syndrome a Meta-Analysis of Individual Patient Data," Journal of the American College of Cardiology, Vol. 55, No. 22, 2010, pp. 2435-2445. doi:10.1016/j.jacc.2010.03.007

[33] E. J. Benjamin, P. A. Wolf, R. B. D'Agostino, et al., "Impact of Atrial Fibrillation on the Risk of Death: The Framingham Heart Study," Circulation, Vol. 98, 1998, pp. 946-952. doi:10.1161/01.CIR.98.10.946

[34] A. N. Mather, T. A. Fairbairn, N. J. Artis, et al., "Relationship of Cardiac Biomarkers and Reversible and Irreversible Myocardial Injury Following Acute Myocardial Infarction as Determined by Cardiovascular Magnetic Resonance," International Journal of Cardiology, 2011. doi:10.1016/j.ijcard.2011.11.004

[35] I. Müller II, K. A. L. Müller, H. Schönleber, et al., "Macrophage Migration Inhibitory Factor Is Enhanced in Acute Coronary Syndromes and Is Associated with the Inflammatory Response," PLOS ONE, Vol. 7, No. 6, 2012, Article ID: e38376. doi:10.1371/journal.pone.0038376

[36] E. Watanabe, T. Arakawa, T. Uchiyama, et al., "HighSensitivity C-Reactive Protein Is Predictive of Successful Cardioversion for Atrial Fibrillation and Maintenance of
Sinus Rhythm after Conversion," International Journal of Cardiology, Vol. 108, No. 3, 2006, pp. 346-353. doi:10.1016/j.ijcard.2005.05.021

[37] A. S. Antonopoulos, M. Margaritis, R. Lee, et al., "Statins as Anti-Inflammatory Agents in Atherogenesis: Molecular Mechanisms and Lessons from the Recent Clinical Trials," Current Pharmaceutical Design, Vol. 18, No. 11, 2012, pp. 1519-1530. doi:10.2174/138161212799504803

[38] G. Ramani, M. Zahid, C. B. Good, et al., "Comparison of Frequency of New-Onset Atrial Fibrillation or Flutter in Patients on Statins versus Not on Statins Presenting with Suspected Acute Coronary Syndrome," American Journal of Cardiology, Vol. 100, No. 3, 2007, pp. 404-405. doi:10.1016/j.amjcard.2007.03.034

[39] M. Ozaydin, Y. Turker, D. Erdogan, et al., "The Association between Previous Statin Use and Development of Atrial Fibrillation in Patients Presenting with Acute Coronary Syndrome," International Journal of Cardiology, Vol. 141, No. 2, 2010, pp. 147-150. doi:10.1016/j.ijcard.2008.11.172

[40] M. D. Miedema, C. A. Conover, H. MacDonald, et al., "Pregnancy-Associated Plasma Protein-A Elevation in Patients with Acute Coronary Syndrome and Subsequent Atorvastatin Therapy," American Journal of Cardiology, Vol. 101, No. 1, 2008, pp. 35-39. doi:10.1016/j.amjcard.2007.07.045

[41] D. Al Khdair, L. Alshengeiti, B. Elbarouni, et al. (Global Registry of Acute Coronary Events (GRACE/GRACE2) and Canadian Registry of Coronary Events (CANRACE) Investigators), "Management and Outcome of Acute Coronary Syndrome Patients in Relation to Prior History of Atrial Fibrillation," Canadian Journal of Cardiology, Vol. 28, No. 4, 2012, pp. 443-449. doi:10.1016/j.cjca.2011.12.011 